\title{
Non-visualized sentinel nodes in breast cancer patients; prevalence, risk factors, and prognosis
}

\author{
N. C. Verheuvel ${ }^{1} \cdot$ A. C. Voogd ${ }^{2,3,4}$ (D) V. C. G. Tjan-Heijnen ${ }^{2} \cdot$ S. Siesling ${ }^{4,5} \cdot$ \\ R. M. H. Roumen ${ }^{1,2}$
}

Received: 3 July 2017/Accepted: 23 August 2017/Published online: 31 August 2017

(c) The Author(s) 2017. This article is an open access publication

\begin{abstract}
Background Evidence and consensus is lacking in international guidelines regarding axillary treatment recommendations for patients in whom a sentinel lymph node (SLN) cannot be visualized (non-vSLN) during the sentinel node procedure. In this study we aimed to determine the prevalence of non-vSLNs in a Dutch population of breast cancer patients and to examine predictors and survival rate for non-vSLN.

Methods A nationwide, retrospective, population-based study was performed including 116,920 patients with invasive breast cancer who underwent a SLN procedure in the Netherlands between January 2005 and December 2013.
\end{abstract}

The contents of this article have been presented in a poster presentation at the San Antonio Breast Cancer Symposium 2016.

$\triangle$ A. C. Voogd

adri.voogd@maastrichtuniversity.nl

1 Department of Surgery, Máxima Medical Center, Veldhoven, The Netherlands

2 Department of Medical Oncology, School for Oncology and Developmental Biology (GROW), Maastricht University Medical Center, Maastricht, The Netherlands

3 Department of Epidemiology, School for Oncology and Developmental Biology (GROW), Maastricht University Medical Center, P.O. Box 616, 6200 MD Maastricht, The Netherlands

4 Department of Research, Netherlands Comprehensive Cancer Organization (IKNL), Utrecht, The Netherlands

5 Department of Health Technology and Services Research, MIRA Institute for Biomedical Technology and Technical Medicine, University of Twente, Enschede, The Netherlands
Results Of the 76,472 clinically negative patients who underwent a SLN procedure, 1924 patients $(2.5 \%)$ had a non-vSLN, of whom 1552 (80.7\%) underwent an ALND. Multivariate analysis showed predictive factors for nonvSLN: older age $(p<0.001)$, diagnosis in the period 2005-2009 $(p<0.001)$, larger tumor size $(p=0.003)$, and extensive nodal involvement $(p<0.001)$. Multivariate survival analysis showed a significantly worse survival (HR $1.18,95 \%$ CI $1.03-1.34, p=0.015$ ) for non-vSLNs patients. However, in the non-vSLN group, an ALND was not statistically significantly associated with a better survival (HR 0.96, 95\% CI 0.53-1.75, $p=0.891$ ).

Conclusion Patients with non-vSLNs had less favorable disease characteristics and a worse survival compared to patients with a visualized SLN. Performing an ALND was not associated with a significantly better survival in patients with non-vSLNs. However, further research on the necessity of axillary treatment in this specific patient group is required.

Keywords Non-visualized sentinel nodes · Survival · Axillary dissection

\section{Introduction}

Historically, axillary lymph node dissection (ALND) has been the gold standard to determine the axillary lymph node status in patients with invasive breast cancer. However, an ALND can cause significant morbidity, such as lymphedema, dysesthesia, impairment of mobility, and pain [1-4]. Since the introduction of the sentinel lymph node (SLN) biopsy around 20 years ago, the indication to perform an ALND has constantly been under revision. It has already been established that, due to a low percentage 
of positive non-sentinel axillary lymph nodes, an ALND can be omitted in patients with a negative SLN and in SLN positive patients with micrometastases or isolated tumor cells [3, 5-7]. Moreover, the Z0011 trial, the AMAROS trial and the NSBAP-32 trial have shown that an ALND may be redundant in certain SLN positive patients with macrometastases and could be omitted completely or substituted by axillary radiotherapy [8-10].

However, none of the studies examining the necessity of the ALND included patients in whom the SLN procedure was unsuccessful, meaning that the SLN could not be visualized or retrieved (non-vSLN). The Dutch guideline recommends to perform an immediate ALND in case of a non-vSLN. However, review of the international guidelines reveals discrepancies in treatment recommendations in case of a non-vSLN. This illustrates the lack of consensus regarding the need to perform an ALND [11-16]. With the present study we aim to determine the prevalence of nonvSLNs in a Dutch population of breast cancer patients and to examine differences in clinicopathological characteristics, predictors, and overall survival between those in whom the SLN procedure was not successful (non-vSLN patients) versus patients in whom one or more SLN's were successfully harvested (vSLN patients). We also examined whether performing an ALND is associated with a better survival in patients with a non-vSLN.

\section{Patients and methods}

\section{Study population}

In this nationwide, retrospective, population-based study we selected patients from the Netherlands Cancer Registry, which is a prospective database of all malignancies diagnosed in the Netherlands, based on notification by the Dutch nationwide pathology archive (PALGA) since 1989, containing information directly registered from the patients' medical records in all hospitals in the Netherlands. The use of these data was approved by the NCR Committee of Privacy. We included patients with primary invasive breast cancer treated between January 2005 and December 2013, who had undergone a SLN procedure and did not have clinically palpable lymphadenopathy $\left(\mathrm{cN}_{0}\right)$ or clinically apparent metastases $\left(\mathrm{cM}_{0}\right)$. Patients receiving neo-adjuvant systemic treatment were excluded.

\section{Sentinel node procedure}

The Dutch guideline recommends performing the SLN procedure using a combination of preoperative lymphoscintigraphy with radioactive colloid and a preoperative injection of Patent Blue [11]. Lymphoscintigraphy was performed to visualize, locate and mark the sentinel nodes. At the start of the surgical procedure, usually about $0.5-1 \mathrm{ml}$ of vital blue dye (Patent Blue V, $2.5 \%$ solution) was also injected. After incision, the blue lymphatics were visualized and a handheld gamma-detection probe was used to harvest the sentinel nodes [17]. The results of the sentinel node procedure were registered based on surgical and pathological reports. The procedure was considered unsuccessful if neither lymphoscintigraphy nor Patent Blue resulted in retrieval of a sentinel node.

\section{Data analyses}

The following information was available for all patients: age at time of diagnosis, year of diagnosis, side of the tumor, location of the tumor, clinical TNM-classification, type of surgery (mastectomy versus breast conserving operation), use of adjuvant systemic treatment (hormonal and/or chemotherapy), use of radiotherapy, date of followup/death (complete until January 2014), and vital status. The available data regarding the tumor included: pathological TNM-classification, tumor size, tumor morphology, tumor grade using the Nottingham-modification-scale, and hormone and HER2 receptor status. The location of the tumor was divided into: lateral (lateral lower and upper quadrant), medial (medial lower and upper quadrant), and central, including the nipple. The number of positive axillary lymph nodes was divided into negative, one or two positive lymph nodes (i.e., minimal nodal involvement), and three or more positive lymph node (i.e., extensive nodal involvement).

In the dataset, results of the SLN were reported in five histological categories: (1) negative, (2) isolated tumor cells $(<0.2 \mathrm{~mm})$, (3) micrometastases $(0.2-2 \mathrm{~mm})$, (4) macrometastases $(>2 \mathrm{~mm})$, and (5) non-visualized SLN. This variable was next recoded into: "negative" (categories $1+2$ ), "positive" (categories $3+4$ ), and "nonvisualized" (category 5) [11]. For univariate and multivariate analyses the variable was recoded into "visualized" (categories $1+2+3+4=$ vSLN group) versus "nonvisualized" (category $5=$ non-vSLN group).

In univariate analyses, the Chi square test was used to compare differences in patient and tumor characteristics between non-vSLN versus vSLN patients and in non-vSLN patients who received an ALND versus those who did not. Variables with a $p$ value of $<0.1$ in the univariate analyses were included in multivariate logistic regression analyses in a stepwise backward fashion to identify predictive factors for a non-vSLN. Survival analyses were conducted using the Kaplan-Meier method. The log-rank test was used to compare survival curves. A Cox regression analysis was performed to calculate the Hazard Ratio (HR), adjusting for potential confounders, identified by the 
univariate $\log$-rank tests. A $p$ value of $<0.05$ was considered statistically significant in the univariate and multivariate analyses.

\section{Results}

\section{Prevalence and predictors of non-visualized sentinel nodes}

Figure 1 shows a flow chart of the patient selection. During the years 2005 until 2013, a total of 116,920 patients were diagnosed with invasive breast cancer in the Netherlands. After applying the in- and exclusion criteria, a total of $76,472(65.4 \%)$ patients who had undergone a SLN procedure remained available for the study. Their median age at diagnosis was 60 years, ranging from 19 to 98 years. In $6912(9 \%)$ patients the SLN procedure was performed, but details on the outcome were missing. Of the remaining 69,560 patients, 16,344 (23.5\%) had a positive SLN biopsy of whom 15,014 (91.9\%) received adjuvant therapy. An ALND was performed in 11,957 (73.2\%) patients of whom $13,354(81.7 \%)$ patients had minimal nodal involvement and $2984(18.3 \%)$ patients had extensive nodal involvement. A negative SLN was found in 51,292 (73.7\%) patients. The SLN group consisted of a total of 67,636 (97.2\%) patients, and was compared with the 1924 (2.5\%) patients in the non-vSLN group (See Fig. 1). Of the 1924 patients with non-vSLNs, $1035(53.8 \%)$ received adjuvant systemic therapy and 1552 (80.7\%) underwent an ALND, of whom $1213(63.0 \%)$ did not have lymph node metastases, $207(10.8 \%)$ had minimal nodal involvement, and $221(11.5 \%)$ had extensive nodal disease. Table 1 shows the distribution of patient and tumor characteristics between non-vSLNs patients versus those with vSLNs and the results of univariate analyses.

In univariate analyses the following factors were associated with a statistically significantly higher $(p<0.10)$ prevalence of non-vSLNs: older age, a diagnosis in the period 2005-2009, mastectomy, a larger tumor size,
Fig. 1 Flow chart of patient selection showing the results of the SLN procedure in clinically node negative Dutch breast cancer patients without metastatic disease between 2005 and 2013

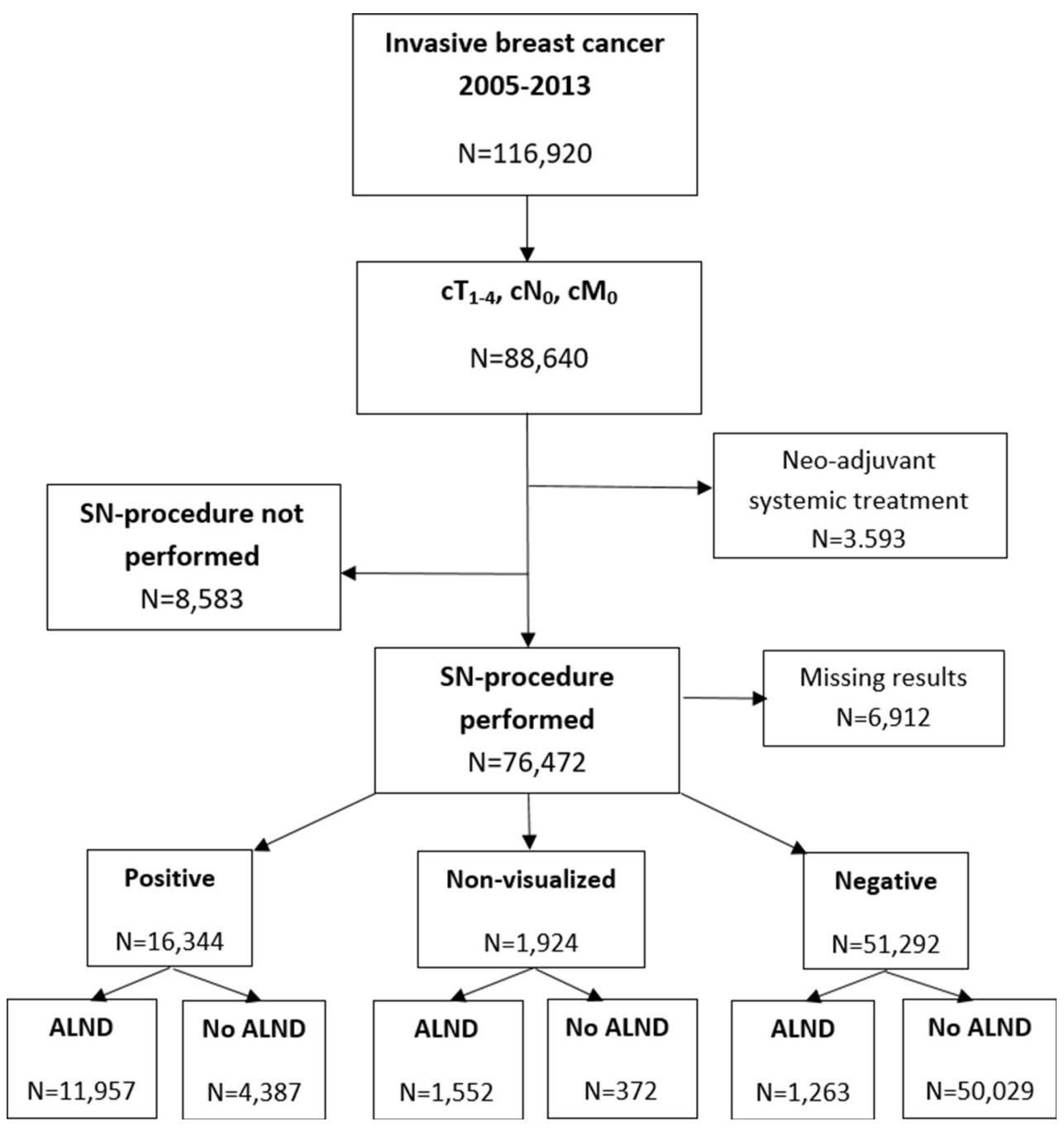


Table 1 Frequency

table showing characteristics of patients with a visualized (vSLN) versus non-visualized sentinel node (non-vSLN)

\begin{tabular}{|c|c|c|c|}
\hline Patient characteristics & $\operatorname{vSLN}(N=67636)$ & Non-vSLN $(N=1924)$ & $p$ value \\
\hline Gender & & & 0.326 \\
\hline Male & $399(0.6 \%)$ & $8(0.4 \%)$ & \\
\hline Female & $67,237(99.4 \%)$ & $1916(99.6 \%)$ & \\
\hline Age & & & $<0.001$ \\
\hline Median (range) & $66(19-98)$ & $66(30-93)$ & \\
\hline$<50$ years & $13,854(20.5 \%)$ & $175(9.1 \%)$ & \\
\hline $50-69$ years & $38,278(56.6 \%)$ & $1012(52.6 \%)$ & \\
\hline$\geq 70$ years & $15,504(22.9 \%)$ & $73738.3 \%)$ & \\
\hline Year of diagnosis & & & $<0.001$ \\
\hline 2005-2009 & $30,561(45.2 \%)$ & $1085(56.4 \%)$ & \\
\hline 2010-2013 & $37,075(54.8 \%)$ & $839(43.6 \%)$ & \\
\hline Side of tumor & & & 0.727 \\
\hline Left & $34,524(51.0 \%)$ & $934(48.5 \%)$ & \\
\hline Right & $33,102(48.9 \%)$ & $990(51.5 \%)$ & \\
\hline Unknown & 10 & & \\
\hline Location of tumor & & & 0.273 \\
\hline Centrally (incl. nipple) & $5081(7.5 \%)$ & $145(7.5 \%)$ & \\
\hline Medially & $14,025(20.7 \%)$ & $430(22.3 \%)$ & \\
\hline Laterally & $31,387(46.4 \%)$ & $874(45.4 \%)$ & \\
\hline Unknown & 17,143 & 475 & \\
\hline Type of surgery & & & $<0.001$ \\
\hline Breast conserving & $43,305(64.0 \%)$ & $1119(58.2 \%)$ & \\
\hline Mastectomy & $24,331(36.0 \%)$ & $805(41.8 \%)$ & \\
\hline Tumor size in mm & & & $<0.001$ \\
\hline Median (range) & $15(0-263)$ & $15(0-100)$ & \\
\hline$<20 \mathrm{~mm}$ & $45,672(67.5 \%)$ & $1213(63.0 \%)$ & \\
\hline $20-30 \mathrm{~mm}$ & $14,883(22.0 \%)$ & $459(23.9 \%)$ & \\
\hline$>30 \mathrm{~mm}$ & $5510(8.1 \%)$ & $210(10.9 \%)$ & \\
\hline Unknown & 1571 & 42 & \\
\hline Morphology of tumor & & & 0.508 \\
\hline Ductal carcinoma & $51,484(76.1 \%)$ & $1468(76.3 \%)$ & \\
\hline Lobular carcinoma & $7179(10.6 \%)$ & $207(10.8 \%)$ & \\
\hline Other types & $8973(13.3 \%)$ & $249(12.9 \%)$ & \\
\hline Tumor grade & & & 0.116 \\
\hline Grade 1 & $18,144(26.8 \%)$ & $493(25.6 \%)$ & \\
\hline Grade 2 & $29,588(43.7 \%)$ & $852(44.3 \%)$ & \\
\hline Grade 3 & $17,034(25.2 \%)$ & $511(26.6 \%)$ & \\
\hline Unknown & 2870 & 68 & \\
\hline ER-status & & & 0.444 \\
\hline Negative & $5704(8.4 \%)$ & $181(9.4 \%)$ & \\
\hline Positive & $57,248(84.6 \%)$ & $1641(85.3 \%)$ & \\
\hline Unknown & 4.684 & 102 & \\
\hline PR-status & & & 0.827 \\
\hline Negative & $11,063(16.4 \%)$ & $358(18.6 \%)$ & \\
\hline Positive & $46,042(68.1 \%)$ & $1309(68.0 \%)$ & \\
\hline Unknown & 10,531 & 257 & \\
\hline HER2-status & & & 0.129 \\
\hline
\end{tabular}


Table 1 continued

\begin{tabular}{|c|c|c|c|}
\hline Patient characteristics & $\operatorname{vSLN}(N=67636)$ & Non-vSLN $(N=1924)$ & $p$ value \\
\hline Negative & $56,970(84.2 \%)$ & $1632(84.8 \%)$ & \\
\hline Positive & $7321(10.8 \%)$ & $186(9.7 \%)$ & \\
\hline Unknown & 3345 & 106 & \\
\hline Multifocality & & & 0.346 \\
\hline No & $58,003(85.8 \%)$ & $1668(86.7 \%)$ & \\
\hline Yes & $9057(13.4 \%)$ & $240(12.5 \%)$ & \\
\hline Unknown & 576 & 16 & \\
\hline Number positive lymph nodes & & & $<0.001$ \\
\hline 0 & $50,654(74.9 \%)$ & $1161(60.3 \%)$ & \\
\hline $1-2$ & $13,847(20.5 \%)$ & $189(9.8 \%)$ & \\
\hline $3+$ & $3086(4.6 \%)$ & $202(10.5 \%)$ & \\
\hline Unknown & 49 & 372 & \\
\hline Adjuvant systemic therapy & & & $<0.001$ \\
\hline No & $27,992(41.4 \%)$ & $889(46.2 \%)$ & \\
\hline Yes & $39,644(58.6 \%)$ & $1035(53.8 \%)$ & \\
\hline Chemotherapy & $7060(17.8 \%)$ & $141(13.6 \%)$ & \\
\hline Hormone therapy & $16,386(41.3 \%)$ & $560(54.1 \%)$ & \\
\hline Both & $16,198(40.9 \%)$ & $334(17.4 \%)$ & \\
\hline Adjuvant radiation therapy & & & 0.010 \\
\hline No & $2022(3.0 \%)$ & $680(35.3 \%)$ & \\
\hline Yes & $45,614(67.4 \%)$ & $1244(64.7 \%)$ & \\
\hline Unknown & 20,000 & 0 & \\
\hline
\end{tabular}

$v S L N$ visualized sentinel node, non-vSLN non-visualized sentinel node, ER-status estrogen receptor status, $P R$-status progesterone receptor status

extensive nodal involvement, and the absence of systemic therapy and radiotherapy. These factors were included in the multivariate logistic regression analysis, which showed that being diagnosed between in the period 2005-2009, being older, having larger tumors, and more often having extensive nodal involvement were predictors for a nonvSLN (Table 2).

\section{Survival of patients with visualized versus non- visualized sentinel nodes}

The median follow-up time of all patients was 3.3 years, with a maximum of 9 years. A total of 4802 patients had died, of whom $244(5.1 \%)$ had non-vSLNs $(p<0.001)$. Survival analyses showed a 5-year survival rate of $91.3 \%$ (95\% CI 91.1-91.5) for the vSLN group versus $86.1 \%$ (95\% CI 84.2-88.2) for the non-vSLN group $(p<0.001)$ (Fig. 2). In the multivariate Cox regression analysis, adjusting for age at diagnosis, year of diagnosis, type of surgery, tumor size, number of positive lymph nodes, adjuvant systemic therapy, and radiotherapy, a worse survival was observed for patients with non-vSLNs compared to those with vSLN patients, with a hazard ratio (HR) of 1.18 (95\% CI $1.03-1.34, p=0.015)$.
Table 2 Multivariate analyses showing various predictive characteristics for a non-visualized sentinel node

\begin{tabular}{llr}
\hline Characteristics & \multicolumn{2}{l}{ Multivariate analysis } \\
\cline { 2 - 3 } & Adjusted OR (95\% CI) & $p$ value \\
\hline Age & 1 & $<0.001$ \\
$\quad<50$ years & $2.19(1.84-2.60)$ & \\
50-69 years & $3.73(3.12-4.46)$ & \\
$\geq 70$ years & & \\
Year of diagnosis & 1 & \\
2005-2009 & $0.50(0.45-0.56)$ & \\
$2010-2013$ & & \\
Tumor size in mm & 1 & $<0.003$ \\
$\quad<20$ mm & $1.18(1.05-1.33)$ & \\
$20-30$ mm & $1.28(1.08-1.52)$ & \\
$>30$ mm & & \\
Number positive lymph nodes & & \\
0 & 1 & \\
$1-2$ & $0.62(0.54-0.73)$ & \\
$3+$ & $2.86(0.44-3.35)$ & \\
\hline
\end{tabular}

We also performed a sensitivity analyses, in which we excluded patients of 70 years or older. Multivariate Cox regression analyses, adjusting for age, year of diagnosis, 


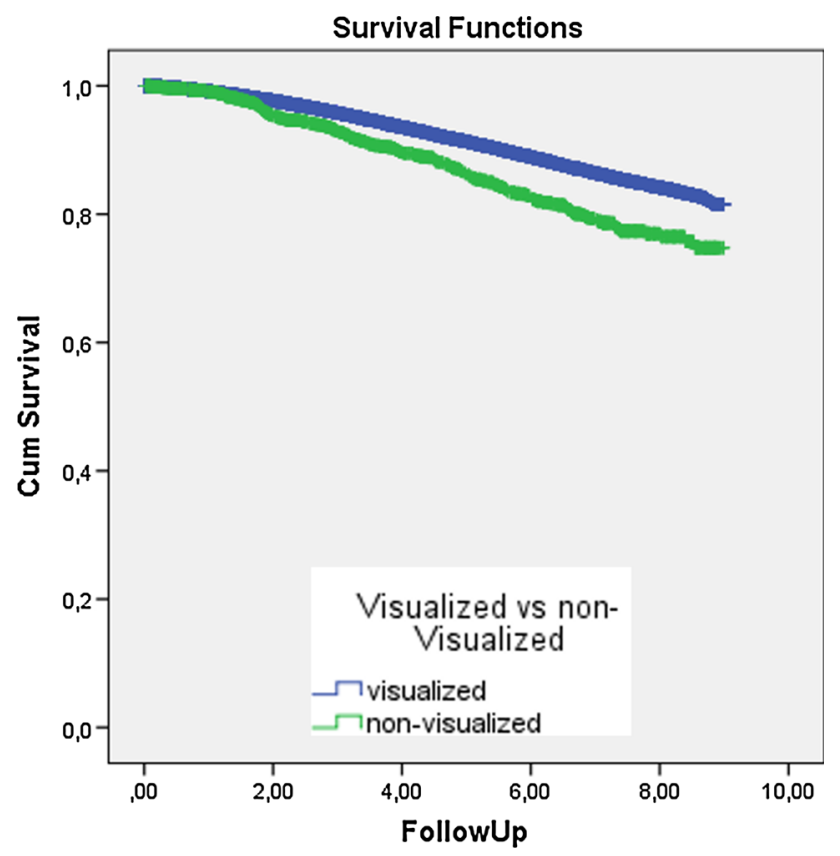

Fig. 2 Kaplan-Meier curves on overall survival in years of patients with non-visualized sentinel lymph nodes (non-vSLN) versus those after with a visualized lymph node (vSLN) $(p<0.001)$

type of surgery, tumor size, progesterone status, number of positive lymph nodes, and adjuvant systemic therapy, showed that even after excluding these older patients, patients with a non-vSLN still had a worse overall survival compared to those with a vSLN (HR 1.42 95\% CI $1.15-1.75$ ).

\section{ALND in patients with non-vSLN and association with overall survival}

Of the 1924 patients with a non-vSLN 1552 (80.7\%) underwent an ALND. Table 3 shows the distribution of patient and tumor characteristics in non-vSLN patients with versus without an ALND and the results of univariate and multivariate logistic regression analyses comparing both groups (with and without ALND). The results of the multivariate analyses showed that patients who underwent an ALND were more often diagnosed in the years 2005-2009 and had larger and more often multifocal tumors.

The 5-year survival rate of patients with an ALND was $85.6 \%$ (95\% CI $79.2-92.0$ ), compared to $86.0 \%$ (95\% CI 84.0-88.0) for those without an ALND $(p=0.692)$ (Fig. 3). A multivariate Cox regression analysis, adjusting for age, year of diagnosis, tumor location, tumor size, ER and PR-status, and adjuvant systemic therapy, did not show a statistically significant difference in survival between patients with and without ALND (HR 0.96, 95\% CI $0.53-1.75, p=0.891)$.

\section{Discussion}

The present study shows that the SLN could not be visualized in $2.5 \%$ of all clinically node negative Dutch breast cancer patients who underwent a SLN procedure. Patients with a non-vSLN were older, were more often diagnosed in the earlier period of 2005-2009, had larger tumors, and were more likely to have extensive nodal involvement, compared to patients who had undergone a successful SLN procedure. Multivariate survival analysis, correcting for the most relevant confounding factors, showed a significantly poorer 5-year survival rate for patients with a non-vSLN versus those with a successful SLN procedure. Moreover, the majority of non-vSLN patients underwent an ALND. These patients more often had larger and multifocal tumors and were more likely to be diagnosed in the early period of 2005-2009, compared to those who did not undergo an ALND. Thus, the present data indicate that this specific group of patients in whom a SLN cannot be successfully visualized and harvested, represents a different breast cancer population.

It has been reported that several factors could influence the success rate of the SLN procedure. First, next to older age, a high body weight appears to result in an increased likelihood for a non-vSLN. It has been hypothesized that lymph nodes in older or more obese patients consist of more fat which decreases the nodes' capacity for colloid uptake [18-20]. Although there was no information on body weight in the present study, this study did show an increased likelihood of non-vSLN with increasing age. Secondly, studies have confirmed our findings that a larger tumor size increases the risk of a non-vSLN. Some have reported that a central location of the breast tumor may increase the chance of a non-vSLN, though this could not be confirmed in the present study [19,21]. Thirdly, a high number of positive lymph nodes and macrometastases is reported to also decrease the success rate of the SLN procedure, which is confirmed in this study [22-24]. This may be caused by blockage of the lymphatic pathways by the enlarged lymph nodes, which causes the lymphatic system to create alternative pathways. Finally, other factors that have been associated with the rate of SLN visualization refer to various procedural factors. SLN identification and visualization is lower during repeat SLNB in patients who previously underwent a SLNB or ALND [25]. The SNARB study (Sentinel Node and Recurrent Breast Cancer) by Vugts et al, which is a multicenter study on the feasibility and clinical usefulness of the repeat SLNB, showed that the limited SLN visualization may be caused by previous radiotherapeutic treatment. In addition, it was advised to inject a larger amount of radioactive dye and a 1-day protocol for lymphoscintigraphy was proposed 
Table 3 Frequency table showing characteristics of non-vSLN patients $(n=1924)$ who underwent an ALND versus no ALND and the results of multivariate analyses

\begin{tabular}{|c|c|c|c|c|}
\hline Patient characteristics & No ALND $(N=372)$ & $\operatorname{ALND}(N=1552)$ & $p$ value & Multivariate analyses OR $(95 \% \mathrm{CI})$ \\
\hline Age & & & 0.058 & \\
\hline$<50$ years & $22(5.9 \%)$ & $153(9.9 \%)$ & & \\
\hline $50-69$ years & $199(53.5 \%)$ & $813(52.4 \%)$ & & \\
\hline$\geq 70$ years & $151(40.6 \%)$ & $586(37.8 \%)$ & & \\
\hline Year of diagnosis & & & $<0.001$ & \\
\hline $2005-2009$ & $94(25.3 \%)$ & $991(63.9 \%)$ & & 1 \\
\hline 2010-2013 & $278(74.7 \%)$ & $561(36.1 \%)$ & & $0.15(0.11-0.21)$ \\
\hline Location of tumor & & & 0.015 & \\
\hline Centrally (incl. nipple) & $33(8.9 \%)$ & $112(7.2 \%)$ & & \\
\hline Medially & $96(25.8 \%)$ & $334(21.5 \%)$ & & \\
\hline Laterally & $143(38.4 \%)$ & $731(47.1 \%)$ & & \\
\hline Unknown & 100 & 375 & & \\
\hline Type of surgery & & & 0.259 & \\
\hline Breast conserving & $226(60.8 \%)$ & $893(57.5 \%)$ & & \\
\hline Mastectomy & $146(39.2 \%)$ & $659(42.5 \%)$ & & \\
\hline Tumor size in $\mathrm{mm}$ & & & $<0.001$ & \\
\hline$<20 \mathrm{~mm}$ & $275(73.9 \%)$ & $938(60.4 \%)$ & & 1 \\
\hline $20-30 \mathrm{~mm}$ & $55(14.8 \%)$ & $404(26.0 \%)$ & & $1.75(1.11-2.76)$ \\
\hline$>30 \mathrm{~mm}$ & $33(8.9 \%)$ & $177(11.4 \%)$ & & $1.72(0.94-3.13)$ \\
\hline Unknown & 9 & 33 & & \\
\hline Morphology of tumor & & & 0.844 & \\
\hline Ductal carcinoma & $283(76.1 \%)$ & $1185(76.4 \%)$ & & \\
\hline Lobular carcinoma & $38(10.2 \%)$ & $169(10.9 \%)$ & & \\
\hline Other types & $51(13.7 \%)$ & $198(12.8 \%)$ & & \\
\hline Tumor grade & & & 0.179 & \\
\hline Grade 1 & $105(28.2 \%)$ & $388(25.0 \%)$ & & \\
\hline Grade 2 & $156(41.9 \%)$ & $696(44.8 \%)$ & & \\
\hline Grade 3 & $86(23.1 \%)$ & $425(27.4 \%)$ & & \\
\hline Unknown & 25 & 43 & & \\
\hline ER-status & & & 0.036 & \\
\hline Negative & $23(6.2 \%)$ & $158(10.2 \%)$ & & \\
\hline Positive & $314(84.4 \%)$ & $1327(85.5 \%)$ & & \\
\hline Unknown & 35 & 67 & & \\
\hline PR-status & & & $<0.001$ & \\
\hline Negative & $37(9.9 \%)$ & $321(20.7 \%)$ & & \\
\hline Positive & $258(69.4 \%)$ & $1051(67.7 \%)$ & & \\
\hline Unknown & 77 & 180 & & \\
\hline HER2-status & & & 0.651 & \\
\hline Negative & $321(86.3 \%)$ & $1311(84.5 \%)$ & & \\
\hline Positive & $34(9.1 \%)$ & $152(9.8 \%)$ & & \\
\hline Unknown & 17 & 89 & & \\
\hline Multifocality & & & 0.093 & \\
\hline No & $334(89.8 \%)$ & $1334(86.0 \%)$ & & 1 \\
\hline Yes & $37(9.9 \%)$ & $203(13.1 \%)$ & & $2.52(1.29-4.90)$ \\
\hline Unknown & 1 & 15 & & \\
\hline Adjuvant systemic therapy & & & 0.003 & \\
\hline No & $198(53.2 \%)$ & $691(44.5 \%)$ & & \\
\hline Yes & $174(46.8 \%)$ & $861(55.5 \%)$ & & \\
\hline
\end{tabular}


Table 3 continued

\begin{tabular}{|c|c|c|c|c|}
\hline Patient characteristics & No ALND $(N=372)$ & $\operatorname{ALND}(N=1552)$ & $p$ value & Multivariate analyses OR $(95 \% \mathrm{CI})$ \\
\hline Chemotherapy & $22(12.6 \%)$ & $119(13.8 \%)$ & & \\
\hline Hormone therapy & $118(67.8 \%)$ & $442(28.5 \%)$ & & \\
\hline Both & $34(19.5 \%)$ & $300(34.8 \%)$ & & \\
\hline Adjuvant radiation therapy & & & 0.250 & \\
\hline No & $141(37.9 \%)$ & $539(34.7 \%)$ & & \\
\hline Yes & $231(62.1 \%)$ & $1013(65.3 \%)$ & & \\
\hline
\end{tabular}

ER-status estrogen receptor status, PR-status progesterone receptor status

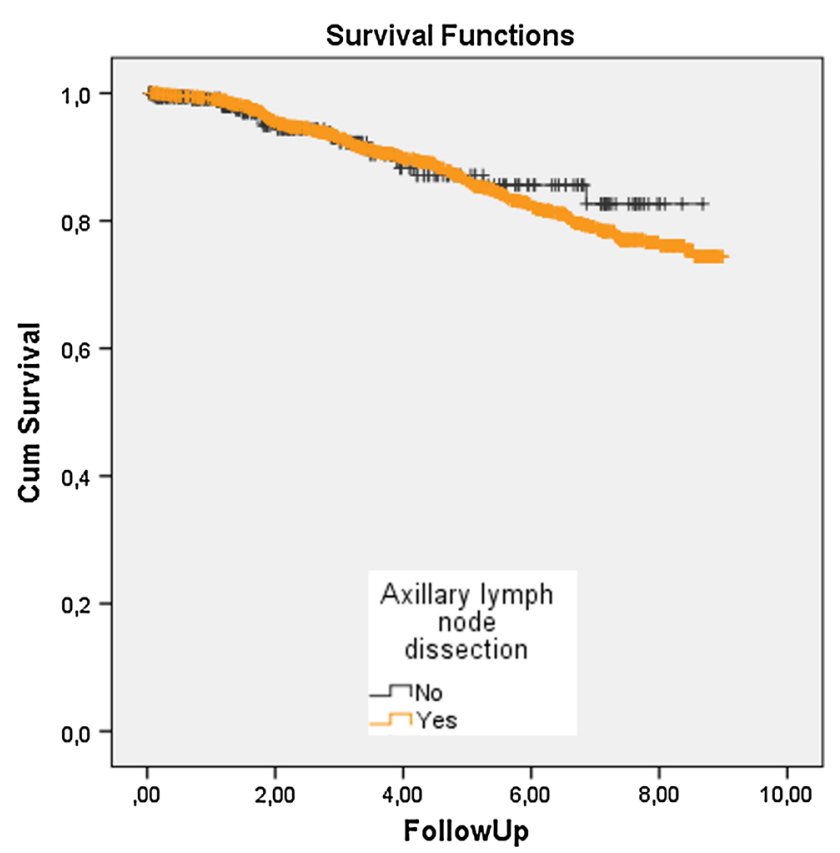

Fig. 3 Kaplan-Meier curves of overall survival in years of non-vSLN patients with versus without ALND $(p=0.692)$

instead of the current 2-day protocol to increase the visualization rate [26]. Studies also show that the success rate of the SLN procedure increases when both the lymphoscintigraphy and Patent Blue methods are used and when a larger amount of radioactive dye is injected [23, 27-29]. Finally, the experience of the surgeon in performing the SLN procedure is important in finding and identifying the lymphatic pathways and the SLN [30]. However, these latter factors were not addressed in the present study.

A clinically important question is whether patients with a non-vSLN should undergo an ALND. International guidelines differ in their treatment recommendations in case of a non-vSLN, if treatment options are mentioned at all. The European ESMO guidelines and the British NICEguidelines both do not mention the possibility of a nonvSLN or its implications at all [12, 13]. The Dutch
NABON-guideline, the American ASCO-guideline, and the Australian guideline all recommend to perform an ALND in case of a non-vSLN $[11,14,15]$. The NCCN guideline agrees with this statement; however, a footnote is added which states that in case of treatment with adjuvant radiation therapy, an extended radiation field to the axilla may also be sufficient [16]. Clinical data to substantiate these statements are very scarce.

Thus, the question remains whether the ALND is required in case of a non-vSLN. Obviously, axillary treatment can be omitted in case of a negative SLN. More recently, research also showed that the ALND could also be omitted in selected SLN positive patients [8-10]. The Z0011 trial formulated criteria to select SLN positive patients in whom the axillary treatment could be omitted without affecting (disease-free) survival [8]. However, the applicability of these criteria to non-vSLN patients is uncertain. In a previous study applying the Z0011 based criteria on a large cohort of Dutch breast cancer patients, more than half of the subgroup of non-vSLN patients who had undergone an ALND appeared to have no axillary lymph node metastases[31]. On the other hand, although in that study $37.2 \%$ of the patients with non-vSLNs had extensive nodal involvement, no statistically significant improved survival after an ALND could be shown. The present study, however, indicates that in non-vSLN patients extensive nodal involvement may be present more often.

The strength of the present study is the combination between analyses of a large national database of breast cancer patients regarding differences in characteristics and survival between vSLN patients and non-vSLN patients, with additional analyses on the impact of an ALND on the overall survival in the non-vSLN group. However, this study also has some limitations. Due to the use of a national database, some data were missing. Furthermore, the SLN procedure was registered as having been performed when either a lymphoscintigraphy and/or the Patent Blue technique was used. However, it was unknown whether both techniques or only one was used in the individual cases. Finally, there was of course a risk of selection bias when comparing the survival in the non-vSLN group 
between patients who did or did not receive an ALND. Also, due to the relatively small number of patients in these subgroups, confidence intervals of the hazard ratios were wide and a clinically relevant difference in survival thus cannot be ruled out.

\section{Conclusion}

In $2.5 \%$ of the patients who underwent a SLN procedure, the sentinel node could not be visualized and harvested. These non-vSLN patients had a worse survival compared to patients with a successful SLN procedure. Subsequently, 80.7\% of these non-vSLN patients underwent an ALND. However, an ALND was not statistically significantly associated with a better survival. Therefore, we conclude that performing an ALND in patients with a non-vSLN is disputable, and that more confirmative research is needed to reach consensus regarding recommendations for axillary treatment in these patients.

Acknowledgements The authors thank the registration teams of the Comprehensive Cancer Centre Netherlands and Comprehensive Cancer Centre South for the collection of data for the Netherlands Cancer Registry and the scientific staff of the Comprehensive Cancer Center Netherlands.

\section{Compliance with ethical standards}

Conflict of interest The authors declare that they have no conflict of interest.

Open Access This article is distributed under the terms of the Creative Commons Attribution 4.0 International License (http://crea tivecommons.org/licenses/by/4.0/), which permits unrestricted use, distribution, and reproduction in any medium, provided you give appropriate credit to the original author(s) and the source, provide a link to the Creative Commons license, and indicate if changes were made.

\section{References}

1. Coufal O, Pavlik T, Fabian P et al (2009) Predicting non-sentinel lymph node status after positive sentinel biopsy in breast cancer: what model performs the best in a Czech population? Pathol Oncol Res 15:733-740

2. Wada N, Imoto S (2008) Clinical evidence of breast cancer micrometastasis in the era of sentinel node biopsy. Int $\mathrm{J}$ Clin Oncol 13:24-32

3. Gur AS, Unal B, Johnson R et al (2009) Predictive probability of four different breast cancer nomograms for nonsentinel axillary lymph node metastasis in positive sentinel node biopsy. J Am Coll Surg 208:229-235

4. Coutant C, Morel O, Antoine M et al (2007) Is axillary lymph node dissection always necessary in breast cancer patients with a positive sentinel node? J Chir (Paris) 144:492-501

5. Cripe MH, Beran LC, Liang WC et al (2006) The likelihood of additional nodal disease following a positive sentinel lymph node biopsy in breast cancer patients: validation of a nomogram. Am J Surg 192:484-487

6. Galimberti V, Cole BF, Zurrida S et al (2013) Axillary dissection versus no axillary dissection in patients with sentinel-node micrometastases (IBCSG 23-01): a phase 3 randomised controlled trial. Lancet Oncol 14:297-305

7. Galimberti V, Manika A, Maisonneuve P et al (2014) Long-term follow-up of 5262 breast cancer patients with negative sentinel node and no axillary dissection confirms low rate of axillary disease. Eur J Surg Oncol 40:1203-1208

8. Giuliano AE, Hunt KK, Ballman KV et al (2011) Axillary dissection vs no axillary dissection in women with invasive breast cancer and sentinel node metastasis: a randomized clinical trial. JAMA 305:569-575

9. Krag DN, Anderson SJ, Julian TB et al (2007) Technical outcomes of sentinel-lymph-node resection and conventional axillary-lymph-node dissection in patients with clinically nodenegative breast cancer: results from the NSABP B-32 randomised phase III trial. Lancet Oncol 8:881-888

10. Rutgers EJT, Donker M, Straver ME et al (2013) Radiotherapy or surgery of the axilla after a positive sentinel node in breast cancer patients: final analysis of the EORTC AMAROS trial. J Clin Oncol 31

11. NABON national guideline breast cancer 2.0; Comprehensive Cancer Centre Netherlands (2012). www.oncoline.nl/mamma carcinoom. Accessed 14 June 2016

12. Senkus E, Kyriakides S, Ohno S, Penault-Llorca F, Poortmans P, Rutgers E et al (2015) Primary breast cancer: ESMO Clinical Practice Guidelines for diagnosis, treatment and follow-up. Ann Oncol 26(Suppl 5):v8-v30

13. Murray N, Winstanley J, Bennett A et al (2009) Diagnosis and treatment of advanced breast cancer: summary of NICE guidance. BMJ 338:b509

14. Lyman GH, Giuliano AE, Somerfield MR et al (2005) American Society of Clinical Oncology guideline recommendations for sentinel lymph node biopsy in early-stage breast cancer. J Clin Oncol 23:7703-7720

15. National Breast and Ovarian Cancer Centre (NBOCC) Australia. Recommendations for use of Sentinel node biopsy in early (operable) breast cancer (June 2008); Cancer Australia 2011. www. canceraustralia.gov.au. Accessed 15 June 2016

16. National Comprehensive Cancer Network. NCCN Clinical Practice Guidelines in Oncology (NCCN Guidelines); Breast Cancer (2016). www.nccn.com. Accessed 14 June 2016

17. Roumen RM, Valkenburg JG, Geuskens LM (1997) Lymphoscintigraphy and feasibility of sentinel node biopsy in 83 patients with primary breast cancer. Eur J Surg Oncol 23:495-502

18. Chagpar A, Middleton LP, Sahin AA et al (2005) Clinical outcome of patients with lymph node-negative breast carcinoma who have sentinel lymph node micrometastases detected by immunohistochemistry. Cancer 103:1581-1586

19. Soran A, Falk J, Bonaventura M et al (2007) Does failure to visualize a sentinel node on preoperative lymphoscintigraphy predict a greater likelihood of axillary lymph node positivity? J Am Coll Surg 205:66-71

20. Dordea M, Colvin H, Cox P et al (2013) Clinical and histopathological factors affecting failed sentinel node localization in axillary staging for breast cancer. Surgeon 11:63-66

21. Goyal A, Newcombe RG, Chhabra A et al (2006) Factors affecting failed localisation and false-negative rates of sentinel node biopsy in breast cancer-results of the ALMANAC validation phase. Breast Cancer Res Treat 99:203-208

22. Brenot-Rossi I, Houvenaeghel G, Jacquemier J et al (2003) Nonvisualization of axillary sentinel node during 
lymphoscintigraphy: is there a pathologic significance in breast cancer? J Nucl Med 44:1232-1237

23. Rousseau C, Classe JM, Campion L et al (2005) The impact of nonvisualization of sentinel nodes on lymphoscintigraphy in breast cancer. Ann Surg Oncol 12:533-538

24. Tanis PJ, Nieweg OE, Valdes Olmos RA et al (2002) Impact of non-axillary sentinel node biopsy on staging and treatment of breast cancer patients. Br J Cancer 87:705-710

25. Maaskant-Braat AJ, Roumen RM, Voogd AC et al (2013) Sentinel Node and Recurrent Breast Cancer (SNARB): results of a nationwide registration study. Ann Surg Oncol 20:620-626

26. Vugts G, Maaskant-Braat AJ, Voogd AC et al (2015) Improving the success rate of repeat sentinel node biopsy in recurrent breast cancer. Ann Surg Oncol 22(Suppl 3):S529-S535

27. Goyal A, Newcombe RG, Chhabra A et al (2006) Factors affecting failed localisation and false-negative rates of sentinel node biopsy in breast cancer-results of the ALMANAC validation phase. Breast Cancer Res Treat 99:203-208
28. McMasters KM, Wong SL, Martin RC et al (2001) Dermal injection of radioactive colloid is superior to peritumoral injection for breast cancer sentinel lymph node biopsy: results of a multiinstitutional study. Ann Surg 233:676-687

29. Heuts EM, van der Ent FW, van der Pol HA et al (2009) Additional tracer injection to improve the technical success rate of lymphoscintigraphy for sentinel node biopsy in breast cancer. Ann Surg Oncol 16:1156-1163

30. Straalman K, Kristoffersen US, Galatius H et al (2008) Factors influencing sentinel lymph node identification failure in breast cancer surgery. Breast 17:167-171

31. Verheuvel NC, Voogd AC, Tjan-Heijnen VC, et al (2016) Potential impact of application of Z0011 derived criteria to omit axillary lymph node dissection in node positive breast cancer patients. Eur J Surg Oncol 42:1162-1168 